\title{
The Wisdom of the Commons: 'Together' is Always Better
}

\author{
Graham Fairclough
}

The idea of commons, quite rightly, has gained an increased currency in recent years. This has happened in many fields, several of which contribute to this collection, but - unsurprisingly given the millennia-long history of landbased commons - it has become increasingly visible in the field of heritageand-landscape discourse as much as in any field. Unfortunately, however, the word 'commons' is far too often prefaced by the words 'tragedy of'. The blame for this rests on a short, misunderstood paper published half a century ago by the American neo-Malthusian ecologist Garret Hardin, to which far too much attention has been paid (Hardin 1968).

So-called 'seminal' works, recurrently cited as the theoretical basis of research, are not uncommon in the literature of landscape and heritage. In some cases, however, their significance is undeserved, and they are not necessarily celebrated for valid reasons. Some - Carl Sauer's (1925) 'The Morphology of Landscape', Marwyn Samuel's (1979) 'Biography of Landscape', perhaps even (at a very different level) Simon Schama's (1995) 'Landscape and Memory' and certainly Garrett Hardin's (1968) 'Tragedy of the Commons' - have been used in ways neither intended nor anticipated by their authors. They are often the work of people from outside the landscape and heritage field, but this is in itself not problematic; all disciplinary visitors are welcome to fields that are

How to cite this book chapter:

Fairclough, G. 2020. The Wisdom of the Commons: 'Together' is Always Better. In Lekakis, S. (ed.) Cultural Heritage in the Realm of the Commons: Conversations on the Case of Greece. Pp. v-xi. London: Ubiquity Press. DOI: https://doi.org/10.5334 /bcj.a. License: CC-BY 
quintessentially inter-disciplinary. What is problematic however is when these scholars' appropriation of the idea of landscape as a metaphor to explore their own topics and to pursue particular agendas are later adopted uncritically by landscape and heritage researchers, and in isolation from their original aims. Written for one precise purpose but thereafter enlisted by others to achieve other goals, these papers can take research in less than helpful directions. Hardin's use of the commons is a sharp point in case; it has proved a major obstacle to the understanding and promotion of commons in a modern context and has distorted how commons are seen.

'The Tragedy of the Commons', Hardin's paper, approaches commons from a negatively ideological perspective. It does not display an accurate understanding of their historical operation because Hardin was not interested in the history or character of commons, and indeed had little useful to say about them. Whatever his influence may have been on environmental science or (post) human ecology, his was a distorted view of commons and their management, used solely to argue for a Malthusian, neo-liberal approach to what he called the 'population problem.' Hardin invented the 'tragedy of the commons' in order to advocate the destruction of commons by modern-day versions of enclosure. For him, commons will (and should) always self-destruct through individual selfishness in order to give way to private enterprise, a natural and inevitable progression because freedom should always be limited. Applying this to population growth, Hardin's mantra was: 'Freedom to breed will bring ruin to all' (Hardin 1968: 1248).

Hardin blamed the breakdown of commons on over-exploitation caused by the selfish behaviour of commoners. As many have since pointed out (Ostrom 1990; Rodgers 2010), however, the failure of commons came almost invariably not from such internal causes but through being engineered by the imposition (during a relatively short period of history) of the external forces of property ownership and incipient capitalism. He chose not to blame the early capitalist landowners who enclosed the commons, nor to recognise that properly managed commons were complex fit-for-purpose systems. For success and sustainability, commons required only careful consensual co-regulation of an area of land and its resources, in other words collaboration, compromise and cooperation.

It is time to stop citing Hardin. The triumph - far from their tragedy - of the commons was their successful maintenance over a very longue durée; there is plenty of evidence in the historical and archaeological record that long-term sustainability can be assured, as in Europe over many centuries if not millennia, when commons are self-regulated by their own community of users for a common good (as evidenced in several chapters in this book, for example Dragouni, Catapoti and Chatzinakos). This applies whether the commons are a tract of rough land for grazing, fuel and other forms of extraction, easily

${ }^{1}$ His other example in the paper was the game of 'noughts and crosses' (tictac-toe, Hardin 1968: 1243), which should have put readers on their guard. 
exhausted shared arable land, water resources, or fish-filled oceans regulated by a 'Common Fisheries Policy'. These of course are all types of resources currently threatened by significant anthropocentric global challenges, and it is interesting that the commons have come back to public awareness precisely at a time of global political and social uncertainty and anxiety. It seems natural that this collection of papers has arisen from Greece in the long aftermath of its post2008 crisis (see notably the chapter by Markopoulos, but additionally those from Kioupkiolis, Chatzinakos or Lekakis), and it also seems appropriate (in a time of the rising urbanisation of human populations) that its main focus is on modern urban contexts, and specifically multi-functional public spaces (see for example, Catapoti et al. and Kioupkiolis).

Commons seem to offer lessons for the $21^{\text {st }}$ century, perhaps even for addressing Hardin's concerns for the impact of overpopulation but in a gentler, more humanistic way. In the $21^{\text {st }}$ century, however, commons come in many forms, from surviving or reconstituted agricultural rural commons to urban commons as the shared spaces of the cities, in the rise of creative ventures in all fields (as well-exemplified by the present collection by Galanos, Travlou or Chatzinakos) and in the deeply political sphere, where (see Kioupkiolis) commons can offer new alternatives of non-hegemonic or heterarchical democracy. As Markopoulos shows, working with the theoretical frame of 'commons' might even enable 'a more radical criticism in politics', challenging the neo-liberal focus on the individual in favour of recognition of the values of collectivity and communalism.

Several chapters in this collection also show commons emerging in the new territories of virtual space, and in digital and cyber realms, indeed also in relation to the growth in acceptance of the ideas of the intangibility of heritage. One of the most intriguing sections in the book is that (Tsiavos) in which Hardin's so-called 'tragedy' silently rears its head again in the digital sphere: the successful digital realms of wiki (-pedia / - media) are closely self-regulated, guided and managed by wiki-communities whereas the problematic platforms (Facebook, Twitter, Instagram) reside firmly in the top-down, neo-liberal market sphere. Digital and virtual commons also open up what is meant by neighbourhood: neighbourliness, being a part of a community, no longer necessarily needs physical proximity. Members of a community (of place or of interest, of landscape or of heritage) are not necessarily always known to each other: the community building OneLoveKitchen was, we are told by Travlou, composed of strangers. This does not exclude physically based neighbourhoods, of course, but complements them.

Commons are increasingly becoming a focus for practical application as well as academic study and increasingly seen as part of a possible way out of current discontent with political systems and their effects. They are becoming highly visible in European Commission funding programmes because, like landscape itself, they inevitably have an interdisciplinary allure. The commons sit at the heart of most humanistic and cultural definitions of landscape, notably of 
the pre-Renaissance, customary definitions, and specifically that of the Landscape Convention (Council of Europe 2000). Landscape is a commons. Equally, conceptualisations and practices of heritage, and not only through critical heritage discourse, are moving towards the idea and value of the commons, in opposition to globalising and neo-liberal currents within World Heritage (and all other spheres, see Kanellopoulou).

Is it possible to turn to any of the existing heritage treaties and conventions to help us frame commons within the heritage field? The UNESCO World Heritage Convention is in this respect of limited help, and understandably perhaps it is almost invisible in this collection of papers (see Lekakis). Arguably it even undermines the idea of commons altogether. UNESCO rhetoric about cultural heritage refers to 'a commitment to preserving our legacy for future generations', rather than to a shared access to heritage for use and enjoyment. While in theory the Convention asks signatory states to inventorise all their heritage, the Convention and its operationalisation) focuses in practice (and in the eyes of a wider public) on selected 'World Heritage' sites - 'outstanding examples' or 'universally significant properties'. This fosters exclusivity on several fronts, notably social and political, but it also privileges a mainly or wholly 'global' scale of value which can be far removed from any concept of commons.

The UNESCO WH Convention does speak of collective assistance and collective protection, but its collectivity arises from an imagined 'international community' rather than from any form of community operating at a more familiarly human level, for example at local or national scale, or through communities of place, interest or heritage. Commons primarily grow from grass-root activity (see for literally grassroots activity Kanellopoulou, or at macro scale Galanos), production and participation (e.g. Chatzinakos), and from use rights (as Kioupkiolis reminds us), and such issues or vectors are not at the forefront of UNESCO thinking (despite UNESCO in 2007 adding 'community' to its strategic objectives - the 'four Cs', previously only Credibility, Conservation, Capacitybuilding and Communication). This is not to deny the achievements of the UNESCO WH Convention since 1972, putting to one side the World Heritage List, in encouraging and supporting non-World Heritage conservation activities and awareness at national or local level. Equally, UNESCO's championship of alternative, more wide-ranging and more globally-sensitive approaches to heritage, notably through its 2003 Convention for the Safeguarding of the Intangible Cultural Heritage and its 2005 Convention for the Protection and Promotion of the Diversity of Cultural Expressions, has enabled heritage to be seen as an important aspect of culture, and culture, and to be treated as a significant type of heritage (UNESCO 2003; 2005). But the 1972 starting point of UNESCO World Heritage Convention is too difficult to reconcile with current ideas of shared heritage, localism and democratic participation to connect to the commons agenda.

Such ideas however are now familiar within the European context in two Council of Europe (not European Union) Conventions concerning Landscape 
(the Florence Convention, the European Landscape Convention (ELC), drafted over many years in the 1990s and finally published in 2000) and Heritage (the Faro Convention). These moved imaginatively towards placing people, citizens and communities at the forefront of their philosophy. The Landscape Convention in 2000 stated in its foundational Preamble that "landscape constitute(s) a common resource", and "contributes to the formation of local cultures ', as 'an important part of the quality of life for people" and "a key element of individual and social well-being”. Furthermore, landscape's 'protection, management and planning entail rights and responsibilities for everyone', an important statement of principle in the context of commons (Council of Europe 2000).

Five years later, the Faro Convention went further. Its title - the Value of Cultural Heritage for Society - clearly stated its broad social, or political, aim. Its Preamble recognised "the need to put people and human values at the centre of an enlarged and cross-disciplinary concept of cultural heritage" as "a resource for sustainable development and quality of life in a constantly evolving society" (Council of Europe 2005). This is in marked contrast to the UNESCO World Heritage Convention which comes close to placing people outside of heritage: in its very first sentence ("heritage ... is increasingly threatened with destruction not only by the traditional causes of decay, but also by changing social and economic conditions") it portrays societal processes - which after all, represent people's aspirations and actions, their everyday lives in effect - as a threat to heritage rather than as a valid use of heritage or as the creative force behind heritage (UNESCO 1972). In contrast, the Faro Convention reflects 'the need to involve everyone in society in the ongoing process of defining and managing cultural heritage'. 'Involvement' (and elsewhere in the Faro Convention 'public or democratic participation', 'shared or public responsibility', and the balancing of rights with responsibilities towards other people) is a deep red thread running through the Convention's text.

Faro (in its Article 3 ) uses the term 'common heritage', as many such documents do, thus risking homogenisation and the heritage marginalisation of less influential, less voiced social groups. But its definition (in Article 2) of heritage as 'a cultural heritage is a group of resources inherited from the past which people identify, independently of ownership' helps to outweigh such risks (Council of Europe 2005). Within the terms of the commons discourse, those words 'independently of ownership' are all-important. They cover the three dimensions of commons to which Kioupkiolis and Lekakis refer in the present collection: the shared-by-all common asset / resource that heritage can be; the use-rights owned by commoners who are not landowners but have long-term intergenerational responsibilities; the processes of commoning, establishing rights and access above and beyond (or at least alongside) legal property ownership.

At the centre of the commons debate, and frequently visible in this collection (for example Dragouni or Lekakis) is the public / private dichotomy, but not straightforwardly. In western Europe, the 'market' (or whatever term is used) is commonly seen as part of the private realm and held distinct from 
and sometimes in opposition to the public sector, yet in the voices heard and reported in these papers the market is seen as an element of the state apparatus and of the public realm, and is held in contradistinction to the private realm of citizens and commons. Perhaps this is a consequence of the special post-crisis situation in Greece. Yet historical commons rarely belonged to everyone in a community but rather to members of a prescribed (often even hereditary) and exclusive group within a community. Where do the commons reside? Commons have traditionally been places of resistance and of opposition, outlaw places and 'no man's land', but at the same time they functioned as part of public resources. Do commons in fact bridge the public / private realms, having feet in both? The 'commune' in republican France is a fusion of public and private, but also a form of the type of decentralised governance which is key to the ideal of commons (and frequently exemplified in this collection). Perhaps the relevant dichotomy is not after all public / private but local / national, in which case the challenge is to prevent modern commons discourse from falling into crude localist or nativist, even nationalistic, views? Can a whole nation act as a commons, in the sense that citizens (or only some of them, to follow historical analogies) possess use rights within the imagined community of a nation state? The papers in this collection that contemplate commons in the virtual, cyber world (Anastasopoulos, Tsiavos) are amongst those most interested in showing what future commons should or might look like, and their imagined communities are not even territorially-based, let alone national.

There are two main sources for optimism within heritage thinking, however, and rather surprisingly one arises from UNESCO. Its recommendations on Historic Urban Landscapes (HUL) (UNESCO 2011), offers a set of ideas that follow in the footsteps of the ELC, with a focus on the 'urban everywhere', on heritage and landscape layering and pluralism, and on democratic participation. The other optimistic path is the Faro Convention on the value of heritage for society, with its refocusing of heritage away from the fabric and materiality of objects towards the people who create and enjoy heritage though ascribing values and associations and through shared use; for this convention heritage is not only objects (the resource of the commons) but also a verb as well as a noun (and thus the process of commoning); while 'societal value' is a simile for useright. Both HUL and Faro seem to stand in support of several of the initiatives and aims described in this rich collection of Greek experience, perhaps most obviously in Chatzinakos' Thessaloniki but in truth in all the papers.

Those two internationally derived but locally-focussed documents are people-centred in ways that many contributors to this book would recognise. They promote forms of ownership of heritage that do not depend on use rights rather than property rights. Strangely, Greece has not signed the Faro Convention (although 24 member states of the Council of Europe have since 2010) - or perhaps it is not strange, given that the Faro is the sort of convention whose influence can be felt and profited from even without the mediation of signatory nation states. It is in short, a form of intellectual commons whose ideas 
are open for all to follow, as this collection does from the perspective of Greek communities looking for new modes of politics. Whilst the papers in this collection, mainly speak of heritage and politics, community and cooperation, it is, finally, important to recall that the historical origins and evolution of commons lie in landscape and its use and that in the $21^{\text {st }}$ century the growing focus on 'landscape approaches' (even if sometimes erroneously called 'nature-based' solutions) is a vehicle through which commons can be reinvigorated. This collection of papers offers inspirational examples and helpful signposts towards new political, social and environmental landscapes.

\section{Bibliography}

Council of Europe. (2000). Council of Europe European landscape convention. Retrieved November 20, 2019, from https://www.coe.int/en/web/landscape. Council of Europe. (2005). Convention on the value of cultural heritage for society (Faro Convention, 2005). Retrieved November 20, 2019, from https:// www.coe.int/en/web/culture-and-heritage/faro-convention.

Hardin, G. (1968). The tragedy of the commons. Science, 162(3859), 1243-1248.

Ostrom, E. (1990). Governing the commons: The evolution of institutions for collective action. Cambridge, United Kingdom: Cambridge University Press.

Rodgers, C. (2010). Reversing the 'tragedy' of the commons?: Sustainable management and the Commons Act 2006. The Modern Law Review, 73(3), 461-486.

Sauer, C. O. (1925). The morphology of landscape. University of California Publications in Geography, 2(2), 19-53.

Samuels, M. S. (1979). The biography of landscape: Cause and culpability. In D. W. Meinig (Ed.), The interpretation of ordinary landscapes: Geographical essays (pp. 51-88). London, United Kingdom: Oxford University Press.

Schama, S. (1995). Landscape and memory. London, United Kingdom: HarperCollins.

UNESCO. (1972). Convention concerning the protection of the world cultural and natural heritage. Retrieved 20 November, 2019, from https://whc.unesco .org/en/conventiontext/.

UNESCO. (2003). Convention for the Safeguarding of the Intangible Cultural Heritage. Retrieved 12 May 2020, from https://ich.unesco.org/doc/src 101852-EN.pdf.

UNESCO. (2005). Convention for the Protection and Promotion of the Diversity of Cultural Expressions. Retrieved 12 May 2020, from https://en.unesco.org /creativity/convention.

UNESCO. (2011). Recommendation on the historic urban landscape. Retrieved 20 November, 2019, from https://whc.unesco.org/uploads/activities /documents/activity-638-98.pdf. 